\section{EMBRYRIDDLE}

Aeronautical University

SCHOLARLY COMMONS
Journal of Aviation/Aerospace Education \& Research

Volume 27

Number 12017 NTAS Conference Selected

Articles

Article 3

2018

\title{
Calculating the Cost of Pilot Turnover
}

Kristine M. Kiernan

Embry-Riddle Aeronautical University, kiern4fd@erau.edu

Follow this and additional works at: https://commons.erau.edu/jaaer

Part of the Business Administration, Management, and Operations Commons, Finance and Financial Management Commons, and the Human Resources Management Commons

\section{Scholarly Commons Citation}

Kiernan, K. M. (2018). Calculating the Cost of Pilot Turnover. Journal of Aviation/Aerospace Education \& Research, 27(1). https://doi.org/10.15394/jaaer.2018.1737

This Article is brought to you for free and open access by the Journals at Scholarly Commons. It has been accepted for inclusion in Journal of Aviation/Aerospace Education \& Research by an authorized administrator of Scholarly Commons. For more information, please contact commons@erau.edu. 


\section{Introduction}

Labor and fuel are typically the greatest cost drivers for airlines (Vasigh, Fleming, \& Mackay, 2017). While some costs of labor are obvious, such as salaries and benefits, other costs are more difficult to quantify. The cost of employee turnover is not immediately clear, but turnover costs in other industries can be as high as $90-200 \%$ of an employee's annual salary (Allen, 2008). Small and regional carriers may be more likely to have high rates of employee turnover, with corresponding heavy cost burdens. The cost of employee turnover has been quantified in other industries (Hinkin \& Tracey, 2000; Jones, 2008), but not yet in the airline industry. Because of the structure of the airline marketplace, costs cannot readily be passed on to consumers. Therefore, high costs erode airlines' often slim profit margins. For airlines, reducing costs can mean the difference between survival and bankruptcy. Airlines that can understand and control their costs at a granular level are the ones that will likely succeed (Saxon \& Weber, 2017).

\section{Purpose of the Research}

This study created a simple model of pilot turnover costs in Part 135 carriers. In addition, this project estimated pilot turnover costs by using data from a Part 135 cargo carrier. Airlines can use this model to determine their own turnover costs.

\section{Background}

\section{Labor Costs in the Airline Industry}

In industries that exhibit cost-based pricing, such as the airline industry prior to deregulation, increased costs are passed on to the consumer in the form of higher prices. However, cost-based pricing is not practical in highly competitive industries with elastic demand, such as the contemporary airline industry (Vasigh, Fleming, \& Tacker, 2013). 
Therefore, increased costs cannot automatically be passed on to the consumer and may instead result in slimmer profit margins. Whether recognized or not, the costs incurred by employee turnover will directly affect the profitability of airlines.

\section{Assessing the Costs of Employee Turnover}

Turnover models in other industries break down costs into different categories, including direct or indirect, visible or invisible, pre-hire and post-hire, or hard and soft costs (Jones, 2008; Society for Human Resource Management [SHRM], 2014).

Most of these models include costs for recruiting, selecting, hiring, training, and filling job vacancies. Many also include the cost of lost productivity, when employees have to drop some of their duties to take on additional work due to jobs that are left vacant. Some models go further and include costs such as loss of organizational knowledge and other negative effects on the work environment. Regardless of which model is used, many of these costs are not visible or easy to quantify. As a result, employers tend to underestimate the cost of turnover ( $\mathrm{O}^{\prime}$ Connell \& Kung, 2007).

\section{Rate of Turnover Across Industries}

The average turnover rate across all industries was 15\% in 2010 (SHRM, 2014). However, turnover rates vary by industry, as shown in Table 1 . At $35 \%$, turnover in the hospitality industry is relatively high, and has therefore, received a lot of attention in the literature. Turnover in nursing is also higher than average, at about 19\% (Jones, 2008). As a result, the nursing literature has begun to focus on the problem of turnover. 
Table 1

Average Annual Turnover by Industry

Industry

Services: accommodation, food and drinking places

Arts, entertainment, and recreation

Retail/wholesale trade

Nursing

All Industries

High-Tech

Government/public

Association - professional/trade

Utilities
Turnover

$35 \%$

$27 \%$

$22 \%$

$19 \%$

$15 \%$

$11 \%$

$9 \%$

$8 \%$

$8 \%$

Note: The rate of employee turnover is calculated as follows: Turnover rate $=$ (Number of terminations [voluntary and involuntary] per year $\div$ Average active employees in that year) x 100 . Adapted from "Executive brief: Differences in employee turnover across key industries" by E. Jacobs, 2011, Society for Human Resource Management. With additional information from "Revisiting nurse turnover costs: Adjusting for inflation" by C. Jones, 2008, Journal of Nursing Administration.

\section{Pilot Turnover}

Little research has been done on pilot turnover. The 2001 Human Resources Study of Commercial Pilots in Canada is one of the few studies that has examined turnover rates in the aviation industry (Air Transport Association of Canada, 2001). The overall turnover rate was not calculated, but $27.4 \%$ of companies surveyed had turnover rates in excess of $30 \%$, as shown in Figure 1.

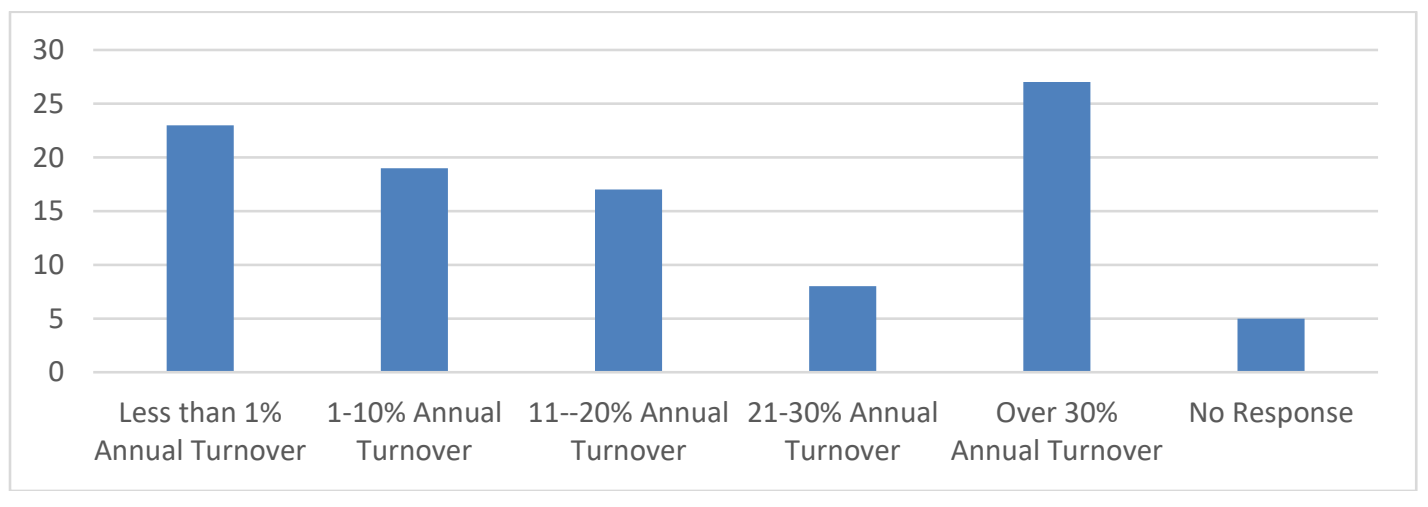

Figure 1. Percentage of companies reporting turnover rates of pilot pool by category. Adapted from "Human Resources Study of Commercial Pilots in Canada" by the Air Transport Association of Canada, 2001. 
When companies were grouped by type of operations, $34 \%$ of air taxi operators, $50 \%$ of cargo operators, and 50\% of commuter operators reported pilot turnover rates in excess of $30 \%$, as shown in Table 2.

Table 2

Turnover Rates as Percentage of Pilot Pool According to Company Type

\begin{tabular}{llllll} 
& Less than $1 \%$ & $1-10 \%$ & $11-20 \%$ & $21-30 \%$ & Over 30\% \\
\hline Specialty Aerial Work & 27.6 & 15.5 & 15.5 & 8.6 & 32.8 \\
Air Taxi & 20.8 & 18.2 & 15.6 & 11.7 & 33.8 \\
Commuter & 5.0 & 5.0 & 30.0 & 10.0 & 50.0 \\
Airline & 0.0 & 37.5 & 25.0 & 0.0 & 37.5 \\
Corp/Private Employers & 34.6 & 15.4 & 15.4 & 11.5 & 23.1 \\
Government & 33.3 & 333.3 & 0.0 & 0.0 & 33.3 \\
Cargo & 10.0 & 20.0 & 15.0 & 5.0 & 50.0 \\
\hline
\end{tabular}

Adapted from "Human Resources Study of Commercial Pilots in Canada" by the Air Transport Association of Canada, 2001.

Research in other industries has shown that per capita turnover costs for positions of high complexity are almost twice as high as for positions of low complexity (Tracey \& Hinkin, 2008). In situations where the labor pool is small, companies also have to spend more money and time on recruitment, again increasing per capita turnover costs (Tracey \& Hinkin, 2008). If turnover rates are high, the total cost for a company in filling positions of high complexity, with a small pool of applicants, can be quite high. Considering these results, Part 135 carriers face a triple threat: the positions for which they hire new pilots are of high complexity; the pool of qualified applicants is small (U.S. Government Accountability Office [GAO], 2014); and evidence suggests that turnover is high (Air Transport Association of Canada, 2001).

\section{Antecedents of Turnover}

In the general workforce, overall job satisfaction is the best predictor of turnover (Griffeth, Hom, \& Gaertner, 2000). Commitment to the job, availability of alternative jobs, and 
job stress are also significant predictors of turnover. Pay is also a significant predictor, but the relationship is not as strong as between turnover and the other antecedents of overall job satisfaction, commitment to the job, availability of alternative jobs, and job stress (Griffeth et al., 2000). The relationship between job satisfaction and retention seems to be mediated by job commitment. In other words, job satisfaction leads to a sense of attachment to the job, which, in turn, positively affects retention.

While the relationship between job satisfaction and retention has not been well studied in aviation, one case study of aerospace engineers showed that challenging work, professional growth, pay, and management practices have the greatest impact on job satisfaction (Applebaum et al., 2003). Work/life balance and non-monetary benefits did not contribute significantly to job satisfaction in this setting. Although this study was in the aviation context, the job description, pay, and work environment for engineers and pilots is sufficiently different that these results cannot be generalized.

Therefore, the relationship between antecedents and turnover may be different among pilots than among workers in other parts of the aviation industry. The low pay for regional and Part 135 pilots has been identified as a critical factor in the failure to attract and retain pilots, particularly as costs for pilot training have increased (Smith, 2017). While an analysis of the drivers of turnover is beyond the scope of this paper, the differential effects of turnover antecedents would be important to research and understand.

Part 135 carriers have traditionally served as stepping stones on the path to employment with major carriers (Smith, 2017). Therefore, the availability of alternative jobs has historically been an important driver of pilots' decisions to leave Part 135 employment. Job stress is 
typically high in these positions, and pay is generally low. Combined, these factors suggest that turnover is probably high among Part 135 carriers.

\section{Impact of Voluntary Separation without Replacement}

In addition to the financial costs of replacing departing employees, many small airlines are now faced with the prospect of being unable to fill the jobs left open. According to the U.S. GAO (2014), 11 of 12 regional airlines contacted reported having difficulty in filling first officer positions. First, the total applicant pool is shrinking. One regional airline executive commented that the number of résumés received in response to pilot job openings has decreased by $90 \%$ (U.S. GAO, 2014). Second, the pilots who do apply have lower overall skill levels than in the past, resulting in a higher rate of attrition from training (U.S. GAO, 2014). In some cases, the pilot vacancies have resulted in cancelled flights, reduced service, and decreased revenues (Bachman, 2014).

\section{Research Methodology}

Several cost of turnover models were examined for their completeness and relevance to the airline setting (SHRM, 2014; Hinkin \& Tracey, 2000; Jones, 2008). Hinkin and Tracey's (2000) model was selected as the most appropriate approach to use for building a pilot-specific model. However, a section on essential data was included, as per the SHRM (2014) model. Hinkin and Tracey's (2000) model divided costs into five categories: separation, recruiting, selection, hiring, and lost-productivity costs. Each item on the Hinkin and Tracey (2000) worksheet, and the essential data section of the SHRM (2014) worksheet, was analyzed to determine an appropriate analog for the position of aircraft pilot. The worksheet that resulted from this effort will be referred to as the Part 135 Pilot Model. 
A Part 135 cargo carrier was selected to provide a case study with which to validate the model. The director of operations for the carrier completed the worksheet using information provided to him by the training and human resources departments.

Where a range of costs existed, for example in hotel and per diem costs, the most conservative, lowest costs were used, so that turnover costs would not be overstated. As a result, the total turnover cost reported represents the minimum actual turnover cost.

\section{Results}

\section{Cost-of-Turnover Model}

The Hinkin and Tracey (2000) model is shown in Appendix A. The Part 135 Pilot Model is shown in Appendix B. The major difference between the models is in the hiring costs category. In the Hinkin and Tracey (2000) model, hiring costs included only two lines for training, which consisted of formal training and on-the-job training. In the Part 135 Pilot Model, however, hiring costs consisted almost entirely of training and included eight separate items: simulator time, simulator instructor time, aircraft time, aircraft instructor time, manuals and charts for new hires, pay for new hire while in training, hotel and per diem for instructors and new hires, and salary of training staff and Director of Training. This reflects the intensity of employer-provided training that distinguishes the airline industry from many others.

The Part 135 Pilot Model also elaborated upon each cost category to allow calculation of per capita turnover costs. Fielding of the model revealed that a section determining annual turnover should be included to help carriers identify the extent of the turnover problem.

\section{Part 135 Cost of Turnover Example}

The actual turnover costs for the Part 135 carrier used in this study are shown in Table 3. The relative cost breakdown for the major categories is shown in Figure 2. 
Table 3

Per Capita Turnover Costs by Category

Cost Category

Separation Per capita cost

Recruiting 770

Selection

1200

Training

Flight training device and simulator cost

Simulator instructor time

Aircraft time

2055

Aircraft instructor time

Manuals and charts

Pay for new hire while in training $\quad 207$

Hotel and per diem for instructors and new hires $\quad 4462$

Per capita cost director of training 706

Lost Productivity

Cost of instructing by pilots not primarily instructors

Vacancy Cost

Travel costs for substitute pilots

Overtime pay for substitute pilots

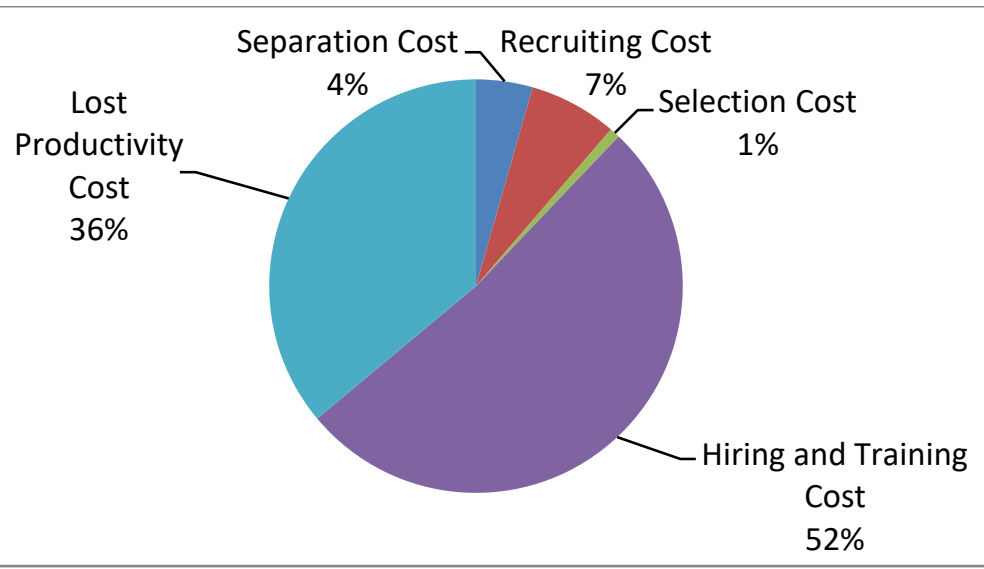

Figure 2. Turnover Costs for Part 135 Carrier by Category.

The cost of turnover was $\$ 17,406$ per employee, which represents $43 \%$ of the average pilot's salary of $\$ 40,000$. The actual pilot turnover rate for the Part 135 carrier used in this study 
was $46 \%$. The total turnover cost for this carrier was calculated but is not presented for confidentiality reasons.

\section{Discussion}

\section{Cost-of-Turnover Model}

The cost-of-turnover model had some unexpected complications. For example, the cost per hour of simulators was challenging because training in some of the aircraft involves company-owned, flight training devices that have only annual costs, while training in other aircraft involve non-company owned simulators that have hourly costs. In order to correctly account for the cost of initial simulator training, the total annual cost for initial training in all devices was divided by the number of pilots who voluntarily departed. This resulted in a per capita turnover cost in the area of simulator training. The different training lengths for different aircraft also posed a challenge. In this case, the average training length was used, since the new hires were relatively evenly distributed between the different aircraft. Companies in which the new hires are not evenly distributed may have to calculate the proportion of new hires in each aircraft.

Another challenge resulted from the difference between fixed, variable, and mixed costs. Fixed costs are those that do not vary with output, while variable costs are those that vary with output, and mixed costs are those that are fixed in some circumstances and variable in others. For example, the salary for a director of training is a fixed cost, as the position is required by Federal Aviation Regulations, regardless of how many pilots are trained. Fuel for an aircraft used for training represents a variable cost, as it increases or decreases with the amount of training that is conducted. Salaries for pilot recruiters is a mixed cost, because while it is fixed over the short term, over time it becomes variable, as fewer staff members are needed as turnover 
decreases. In this model, the per capita turnover costs that are due to mixed costs appear to decrease as turnover increases, since the costs are spread over a larger number of pilots. However, in the long run, these fixed costs actually become variable, which would result in a decrease in per capita turnover costs. However, since the model is based on a cross-sectional observation, it cannot account for the decrease in variable costs over time. Completion of the cost of turnover worksheet required the participation of both the human resources department and the training department. Completing the worksheet took roughly four hours of time from airline personnel, and would not be possible using only publicly available records.

\section{Part 135 Cost of Turnover Example}

The turnover rate of $46 \%$ is consistent with the high rate of turnover found in Canadian cargo and air taxi operators. The rate of turnover at this carrier is higher than the average rate of turnover for all industries, including hospitality, in which turnover is a well-researched and recognized problem (Hinkin \& Tracey, 2000). The percentage of annual salary represented by turnover costs, in this case $43 \%$, is lower than estimates in other industries; although the absolute value of $\$ 17,405$ is higher than the Bureau of Labor Statistics estimate of $\$ 13,966$ for private industry (O'Connell \& Kung, 2007). These facts suggest that while per capita turnover costs for this carrier are not high relative to other industries, the extremely high turnover rate relative to other industries makes total turnover costs high for this Part 135 carrier.

\section{Conclusion}

The Part 135 Pilot Model is a viable method for Part 135 carriers to assess pilot turnover costs. Use of the model to determine actual pilot turnover costs in a Part 135 carrier showed that the turnover rate was $46 \%$, and that turnover costs were $\$ 17,405$ per pilot, which represents $43 \%$ of the average annual pilot's salary. The extremely high turnover rate suggests that turnover is 
an important issue in Part 135 operations, and that turnover costs may represent a financial burden on carriers.

\section{Future Research}

Although the Part 135 Pilot Model proved useful for calculating turnover costs for one carrier, the model should be validated by other subject matter experts. The model can then be fielded more widely to find average turnover costs for Part 135 operators. A similar process can be used to build a model for Part 91 fractional ownership operations, and Part 121 scheduled airline operations. Major Part 121 carriers probably do not face high turnover rates, but smaller regional carriers likely have very high turnover rates.

Turnover and retention also have costs and benefits, which need to be calculated and compared in order to make valid business cases for retention (Jones \& Gates, 2007). Part of calculating the costs of turnover should include researching the effect of turnover on workforce and financial performance, and other metrics critical to aviation, such as safety.

Future research should also be directed towards understanding the causes, types, and consequences, of turnover. For example, answers should be sought for questions such as, who is leaving? Are the pilots we are losing the ones we want to keep? How long do they stay before they leave? Why are they leaving? (Jones, 2008). In human resources theory, job satisfaction builds job commitment, which in turn influences retention. Limited studies that have been in done in aviation settings demonstrate that this kind of data can be gathered relatively easily by individual companies (Applebaum et al., 2003).

In addressing ways to improve retention in aerospace, the American Institute for Aeronautics and Astronautics (AIAA) has made the following recommendations: encourage young employees to share their views, especially through new media; encourage employees' 
input on improving the work environment; create opportunities for mentorship; structure pay on performance and privilege responsibility over seniority (AIAA, 2009). Some of these ideas could be easily implemented. Others, such as structuring pay based on performance, represent a major departure from traditional airline labor practices and might be considered impossible. However, if the problem of recruitment and retention in Part 135 and regional Part 121 operations becomes severe enough, unconventional solutions may have to be considered. 


\section{References}

Air Transport Association of Canada. (2001). Human Resource Study of Commercial Pilots in Canada. Retrieved from http://www.flying-colors.org/ATAC/2793-1.pdf

Allen, D. (2008). Retaining Talent: A Guide to Analyzing and Managing Employee Turnover. Alexandria, VA: SHRM Foundation. Retrieved from https://www.shrm.org/hrtoday/trends-and-forecasting/special-reports-and-expert-views/Documents/RetainingTalent.pdf

American Institute for Aeronautics and Astronautics (AIAA). (2009). Building and retaining the aerospace workforce: Report and recommendations. Retrieved from http://www.aiaa.org/uploadedFiles/Issues_and_Advocacy/Inside_Aerospace09_Report_a nd_Recommendations.pdf

Applebaum, S. H., Wunderlich, J., Greenstone, E., Grenier, D., Shapiro, B., Leroux, D., \& Troeger, F. (2003). Retention strategies in aerospace turnover: A case study. Career Development International, 8(6), 270-282. https://doi.org/10.1108/13620430310496080

Bachman, J. (2014, February 11). Yes, There’s a Pilot Shortage: Salaries Start at \$21,000. BloombergBusinessweek. Retrieved from http://www.businessweek.com/articles/201402-11/yes-theres-a-pilot-shortage-salaries-start-at-21-000

Griffeth, R. W., Hom, P. W., \& Gaertner, S. (2000). A meta-analysis of antecedents and correlates of employee turnover: Update, moderator tests, and research implications for the next millennium. Journal of Management, 26(3), 463-488. https://doi.org/10.1177/014920630002600305 
Hinkin, T. R., \& Tracey, J. B. (2000). The cost of turnover: Putting a price on the learning curve. The Cornell Hotel and Restaurant Administration Quarterly, 41(3), 14-21. https://doi.org/10.1177/001088040004100313

Jones, C., \& Gates, M. (2007). The costs and benefits of nurse turnover: A business case for nurse retention. The Online Journal of Issues in Nursing, 12(3).

Jones, C. B. (2008). Revisiting nurse turnover costs: Adjusting for inflation. Journal of Nursing Administration, 38(1), 11-18. https://doi.org/10.1097/01.NNA.0000295636.03216.6f

O’Connell, M., \& Kung, M.-C. (2007, January). The cost of employee turnover. Industrial Management, (49)1, 14-19.

Saxon, S., \& Weber, M. (2017). A better approach to airline costs. McKinsey \& Co. Travel, Transport and Logistics. Retrieved from https://www.mckinsey.com/industries/traveltransport-and-logistics/our-insights/a-better-approach-to-airline-costs

Smith, P. (2017). The pilot shortage is real and airlines must change before it becomes a fullblown crisis. Business Insider. Retrieved from http://www.businessinsider.com/airlinepilots-reveals-truth-myth-pilot-shortage-2017-7

Society for Human Resource Management (SHRM). (2014). Cost-of-Turnover Worksheet. Retrieved from http://www.shrm.org/templatestools/samples/hrforms/articles/pages/1cms_011163.aspx

Tracey, J. B., \& Hinkin, T. R. (2008). Contextual factors and cost profiles associated with employee turnover. Cornell Hospitality Quarterly, 49(1), 12-27. https://doi.org/10.1177/0010880407310191 
U.S. Government Accountability Office (GAO). (2014, February). Aviation Workforce - Current and Future Availability of Airline Pilots. GAO-14-232. Washington, DC: U.S. Government Printing Office. Retrieved from http://www.gao.gov/assets/670/661243.pdf

Vasigh, B., Fleming, K., \& Mackay, L. (2017). Foundations of airline finance: Methodology and practice. New York, NY: Routledge.

Vasigh, B., Fleming, K., \& Tacker, T. (2013). Introduction to Air Transport Economics $\left(2^{\text {nd }}\right.$ Ed.). Burlington, VT: Ashgate. 


\title{
Appendix A
}

\section{Hinkin and Tracey Model}

\section{Exhibit 1 \\ Turnover-cost categories}

\author{
Separation costs \\ Exit inverviawer \\ Employe oxla inderview \\ Paperwork processing \\ Sevarance pay \\ Aecrulting and attracting costs \\ Advertising \\ Search and agency leess \\ Internal ralerrad lees \\ Managerial pre-employment \\ administrative functions \\ Applitant travel \\ Pecriviter travel \\ Recruviler time \\ Miscellaneous (correspondence, \\ telephone, couriers) \\ HR pre-employment \\ edministrativa functions \\ salnctim eosta \\ HA interview \\ Managerial intorview \\ Applleani traval \\ Background and reference checks \\ Mexcal exam \\ HA adminlgirative lunctions \\ Managerial adminlsirative functions \\ Hiring costs \\ HA administrative lunctions \\ Managerial administrative functions \\ Relocation costs \\ Signing bonks \\ Orientation \\ Formal training \\ On-the-job Iraining \\ Uniforms \\ Security \\ Inlormational literalure \\ Lost pradnethitiy corts \\ Vacancy cost \\ Pro-departure productluity loss \\ Learning curve foost Incurred \\ and lost revenue) \\ Errors and wasie \\ Supervieory disruption \\ Peer disruption
}




\section{Appendix B}

\section{Cost-of-Turnover Worksheet, Part 135 Pilots}

\section{Essential data:}

Annual salary of recruiters (workers whose full time job is pilot hiring):

Annual number of pilots who voluntarily quit:

Annual salary of training staff:

Annual salary of Director of Training:

Hourly wage of instructor pilots:

Hourly wage of simulator instructors:

Hourly cost of simulator:

Hourly cost of operating actual aircraft for training:

Hourly pay for new hire:

\section{Additional information to calculate voluntary and total turnover rate (optional):}

Total number of pilots employed:

Total number of pilots who left in past calendar year, both voluntary and involuntary:

Average annual salary of pilots:

\section{Separation Costs}

- Pay out of vacation/sick leave (average):

\section{Recruiting costs}

- Advertising:

- Travel costs to job fairs: (cost per fair ___ $) \times($ number of fairs per year ___ $)=$ 
- Salary of pilot recruiters: (annual salary ___ $) \times($ number of pilot recruiters ___ $)=$

- Total per capita recruiting costs: (sum of all recruiting costs) $\div$ (total number of pilots who left in past calendar year) $=$

\section{Selection Costs}

- Interviewing by managers other than pilot hiring agents: (managers' hourly wage $\mathrm{x}$ (hours spent interviewing per candidate )$=$

- Background check:

- Drug tests:

- Total per capita selection costs: sum of all selection costs:

\section{Hiring and Training Costs}

- Simulator time: [(hourly cost of simulator___ $)$ x (hours in sim per new hire___ $)] \div$ 2 if 2 new hires trained in same sim session $=$

- Sim Instructor time: [(hourly wage of simulator instructor ___ $)$ x (hours spent instructing per new hire____ $)] \div 2$ if 2 new hires trained in same sim session $=$

- Aircraft time: (hourly cost of aircraft ___ $) \times$ (hours per new hire___ $)=$

- Aircraft instructor time: (hourly extra wage of aircraft instructor ___ $)$ x (hours spent instructing per new hire____ $)=$

- Manuals and charts for new hire:

- Pay for new hire while in training: (hourly wage of new hire ) $x$ (hours spent in training per new hire )$=$

- Hotel and per diem for instructors and new hires (instructor costs shared between 2 new hires): 
O Instructor: $[($ cost per day) $\mathrm{x}$ (days of training) $] \div 2=$

- New Hire: $[($ cost per day $) \mathrm{x}$ (days of training) $]=$

- Per capita cost of training staff and director:

○ Per capita cost of salary of training staff: [(Annual salaries ___ $)$ x (percentage of time spent on new hire training ___ $]+$ total number of pilots who left in past calendar year ___ $=\ldots$ Note: This was not included for case study, as data was uncertain.

○ Salary of director of training: [(Annual salary ___ $)$ x (percentage of time spent on new hire training ___ $)] \div$ total number of pilots who left in past calendar year

- Total per capita hiring costs: (Simulator cost ___ $)+($ simulator instructor time $\ldots+($ aircraft time ___ $)+($ aircraft instructor time ___ $)+($ manuals and charts $\ldots$ and new hires ___ $)+\left(\right.$ per capita cost training staff and director $\_$_ $)$

\section{Lost-Productivity Costs}

- Interviewing by managers whose primary job is not interviewing: (hourly wage of managers ___ $) \times($ hours spent interviewing per candidate ___ $)=$

- Instructing by pilots whose primary job is not instructing: (hourly wage of pilots ) $x$ (hours spent instructing per new hire ___ $)=$

- Instructing for non-revenue flights (this accounts for the fact that instructors flying nonrevenue training flights are not available for revenue flights): (hourly wage of instructor pilots ) (hours spent instructing per new hire on non-revenue flights )$=$ 
- Vacancy cost

- Flying the line by pilots whose primary job is not flying the line: (hourly wage _ $) \times$ (hours spent flying the line ___ $)=$

- Annual travel costs for substitute pilots

- Plane tickets:

- Hotel costs:

- TDY costs:

- Overtime pay for substitute pilots: (hourly incremental overtime pay $\mathrm{x}$ (hours of overtime $=$

- Annual cost of cancellation of flights:

○ Total vacancy costs: (sum of vacancy costs) $\div$ (annual number of pilots who voluntarily quit $)=$

- Total lost productivity costs: sum of interviewing cost, instructing cost, and total vacancy cost:

Total turnover cost per pilot: Separation cost + Recruiting cost + Selection cost + Hiring and Training cost + Lost Productivity cost $=$

Total turnover costs: (Total turnover cost per pilot) $x$ (Total number of pilots who left in past calendar year) $=$

\section{Optional:}

Voluntary turnover rate: [(Total number of pilots who voluntarily left in past calendar year $\div($ Average number of pilots employed $)] \times 100=$ 
Total turnover rate: [(Total number of pilots who left in past calendar year) $\div$ (Average number of pilots employed) $] \times 100=$ 